\title{
Alpha-fetoprotein producing pulmonary blastoma in a patient with systemic sclerosis: pathogenetic analysis
}

\author{
I. Kasuga*, D. Miyamoto*, Y. Ichinose*, W. Chimangul*, K. Minemura*, K. Utsumi*, \\ M. Yonemaru*, H. Serizawa**, Y. Ebihara**, K. Toyama*
}

Alpha-fetoprotein producing pulmonary blastoma in a patient with systemic sclerosis: pathogenetic analysis. I. Kasuga, D. Miyamoto, Y. Ichinose, W. Chimangul, K. Minemura, K. Utsumi, M. Yonemaru, H. Serizawa, Y. Ebihara, K. Toyama. @ERS Journals Ltd 1998. ABSTRACT: We describe a rare case of pulmonary blastoma complicated with systemic sclerosis. The serum $\alpha$-fetoprotein level was elevated at presentation and the biopsied tumour stained positively against anti- $\alpha$-fetoprotein antibody. The $\alpha$-fetoprotein produced autonomously by tumour cells was of yolk-sac origin. Although the pathogenesis of pulmonary blastoma has not been clarified, we suggest that this pulmonary blastoma is a type of yolk-sac tumour.

Eur Respir J 1998; 11: 1185-1187.

\author{
*First Dept of Internal Medicine, **Sec- \\ ond Dept of Pathology, Tokyo Medical \\ College Hospital, Tokyo, Japan. \\ Correspondence: I. Kasuga, First Dept of \\ Internal Medicine, Tokyo Medical Coll- \\ ege, 6-7-1 Nishishinjuku Shinjuku-ku, \\ Tokyo 160-0023, Japan \\ Fax: 81353816651 \\ Keywords: Alpha-fetoprotein, collagen vas- \\ cular disease, pulmonary blastoma, syste- \\ mic sclerosis, yolk sac \\ Received: July 241997 \\ Accepted after revision January 191998
}

Pulmonary blastoma is a rare tumour of the lung composed of immature mesenchyma and epithelium that morphologically mimics the embryonal lung structure. The first report of pulmonary blastoma was made in 1945 [1], and only 50 cases of pulmonary blastomas have been reported to date. The histogenesis of pulmonary blastoma is still unknown because of its rarity. Recently, several pathogenetic possibilities have been proposed, but no definite conclusion has been reached.

\section{Case report}

A 61 yr old female smoker (7-8 cigarettes $\cdot$ day $^{-1}$ for 15 yrs) had suffered from systemic sclerosis for $10 \mathrm{yrs}$. The onset signs were Raynaud's phenomenon and puffy fingers, and systemic sclerosis was confirmed by cutaneous biopsy which showed fibrotic changes in the skin and subcutaneous tissue. No features of the calcinosis, Raynaud's phenomenon, oesophageal dysmotility, sclerodactyly, teleangiectasia (CREST) syndrome were seen during the clinical course. She had received D-penicillamine and corticosteroid treatment in the dermatology department for 3 yrs. She was referred to our department on May 22,1995 , with a one-month history of cough producing bloody sputum.

She was afebrile and had no dyspnoea or cyanosis. Her blood pressure was $150 / 72 \mathrm{mmHg}$ and cardiac frequency 90 beats $\cdot \mathrm{min}^{-1}$ with a regular rhythm. The heart and breath sounds were normal. There were no abnormal neurological findings. The neck and axillary lymph nodes on the left side were firm and swollen. The abdomen was soft with no organomegaly. Cutaneous scleroderma was present on the extremities, face and trunk. Chest radiogra- phy on ad-mission revealed multiple abnormal opacities in both lung fields (fig. 1a). A computed tomography (CT) scan of the chest showed a $3.4 \times 6.6 \mathrm{~cm}$ tumour mass in the left $\mathrm{S}^{9}$ area, which was designated as primary lesion, with multiple metastatic lesions (fig. 1b). Several peripherally sited metastatic lesions have pleural involvement. Fibrotic chan-ges were also recognized in both lower lung fields. The haemoglobin level was $9.2 \mathrm{~g} \cdot \mathrm{dL}^{-1}$ and lactate dehydrogenase was $467 \mathrm{U} \cdot \mathrm{L}^{-1}$. Antinuclear antibodies were strongly positive $(\times 1280$, nucleolar type $)$, but anti-deoxyribonuc-leic acid, anti-ribonucleoprotein (RNP), and anti-scleroderma ( $\mathrm{Scl}$ )-70 antibodies were negative. Hepatitis $B$ virus (HBs) antigen and hepatitis $\mathrm{C}$ virus (HCV) antibody were negative. Liver function parameters were within norm- al limits. Levels of tumour markers associated with lung cancer were high: carcinoembryonic antigen (CEA) was $551.7 \mathrm{ng} \cdot \mathrm{mL}^{-1}$ (normal limit $<3.0 \mathrm{ng} \cdot \mathrm{mL}^{-1}$ ), sialyl lewis $\mathrm{X}_{-} \mathrm{i}$ antigen (SLX) was $120 \mathrm{U} \cdot \mathrm{mL}^{-1}$ (normal limit $<37 \mathrm{U} \cdot \mathrm{mL}^{-1}$ ), cytokeratin 19 fragment (CYFRA) was $29.6 \mathrm{ng} \cdot \mathrm{mL}^{-1}$ (normal limit $<1.0 \mathrm{ng} \cdot \mathrm{mL}^{-1}$ ). In addition, the elevation of ser-um $\alpha$-fetoprotein (AFP) was remarkable, $>80,000 \mathrm{ng} \cdot \mathrm{mL}^{-1}$ (normal limit $<10 \mathrm{ng} \cdot \mathrm{mL}^{-1}$ ).

Fibreoptic bronchoscopy revealed a polypoid lesion in the left main bronchus and stenosis distal to that site. The biopsied specimen of the polypoid lesion revealed the well-differentiated foetal adenocarcinoma variant of pulmonary blastoma (fig. 2). Transbronchial lung biopsy, performed through the left $\mathrm{B}^{9}$ area, showed the same histological findings as the polypoid tissue. There were no abnormalities in any other organs including the liver, ovaries or mediastinum. Immunohistochemical staining of the biopsied specimen by an anti-AFP monoclonal antibody demonstrated many positively stained tumour cells (fig. 3 ). We diagnosed this case as AFP-producing pulmonary 

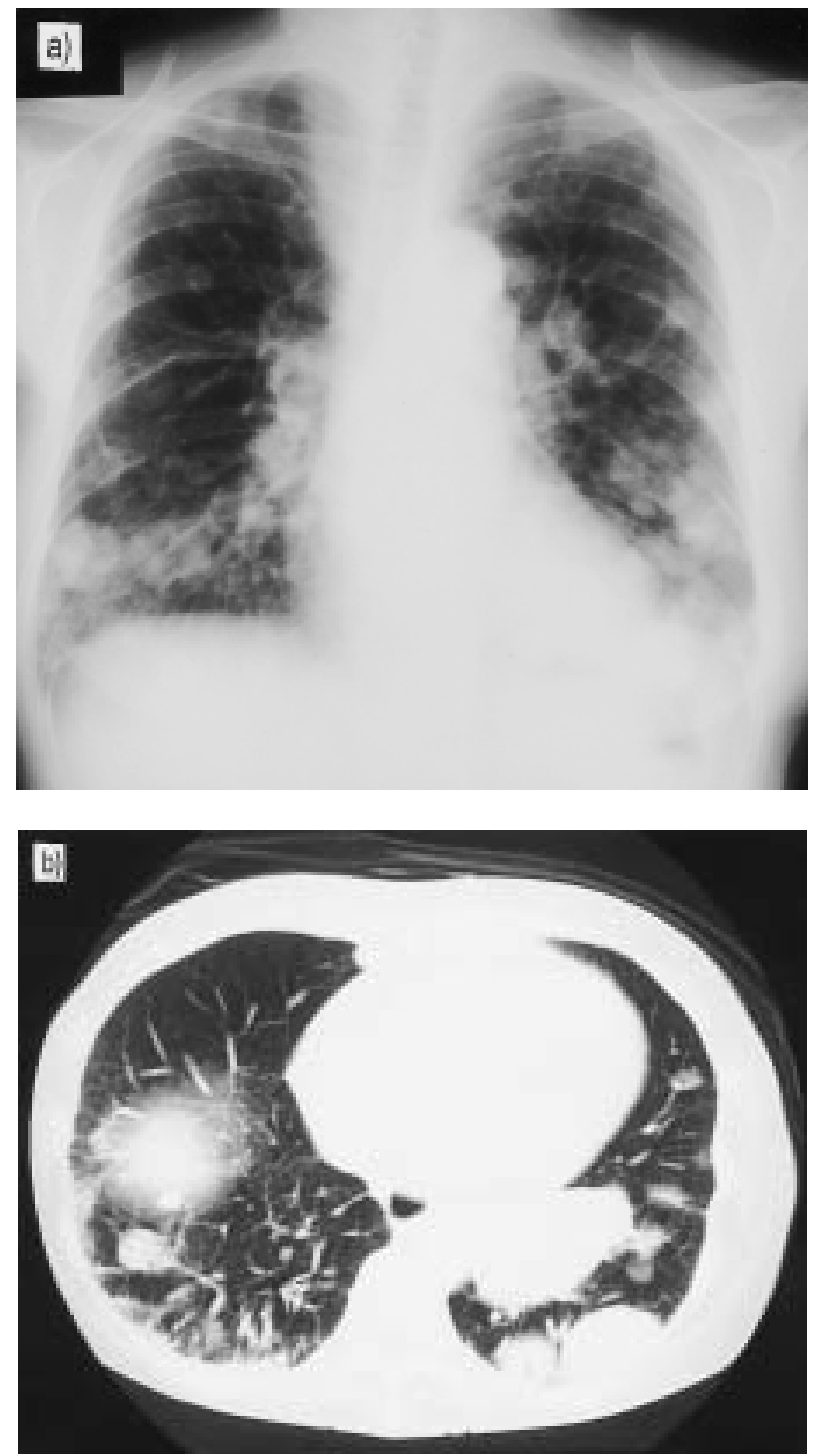

Fig. 1. - a) Chest radiograph revealing multiple tumour lesions with bilateral basal fibrotic changes. b) Chest computed tomography scan showing a $3.4 \times 6.6 \mathrm{~cm}$ primary tumour lesion located in the left $\mathrm{S}^{9}$ area. Multiple metastatic lesions were also demonstrated.

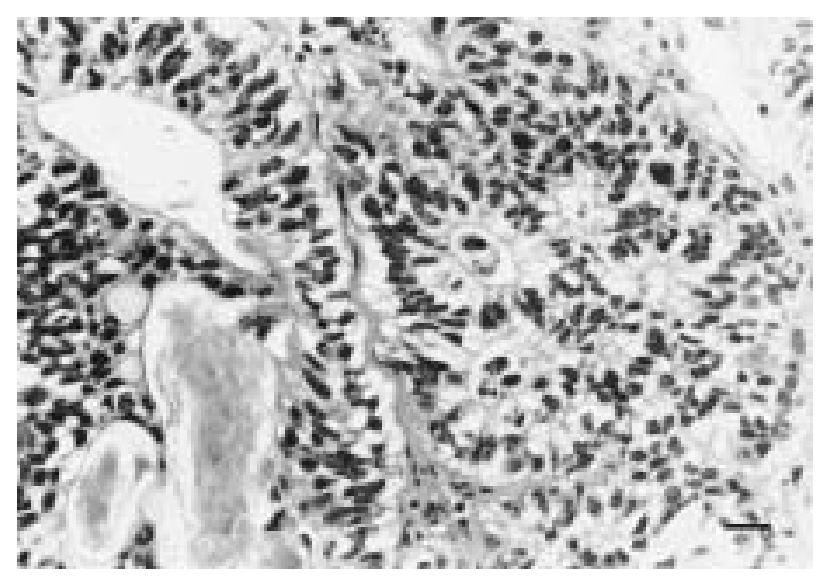

Fig. 2. - Histological specimen revealing obvious glandular structures. The cytoplasm was characteristically clear and contained glycogen, resembling the foetal lung. No sarcomatous elements were identified. Stain: haematoxylin and eosin. (Internal scale bar $=250 \mu \mathrm{m}$ ).

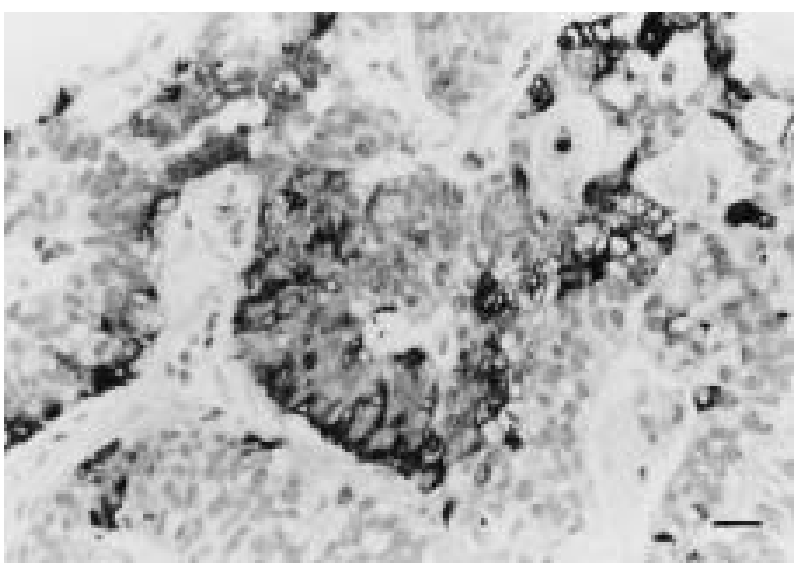

Fig. 3. - Tumour cells were reactive against anti- $\alpha$-fetoprotein monoclonal antibody. Immunohistochemical assays were conducted by the avidin-biotin complex method. (Internal scale bar=250 $\mu \mathrm{m}$ ).

blastoma (stage IV). Systemic chemotherapy combining carboplatin (550 mg.body ${ }^{-1}$, day 1 ) and vindesine (4 mg. body $^{-1}$, days 1 and 8 ) was administered, but no improvement was recognized radiographically. The serum AFP level also remained high $\left(>80,000 \mathrm{ng} \cdot \mathrm{mL}^{-1}\right)$ during her clinical course. Total atelectasis of the left lung then developed and dyspnoea increased gradually. The patient died 6 months after admission.

\section{Discussion}

Pulmonary blastoma is a rare lung neoplasm, characterized by immature mesenchyma and epithelium that resembles the embryonal pulmonary structure of between 10-16 weeks' gestation [2, 3]. Only approximately 50 cases of pulmonary blastomas have been reported to date [4]. Recently, pulmonary blastoma was classified into three subtypes: 1) those with a mesenchymal and epithelial appearance (biphasic blastoma); 2) those with only a sarcomatous component, occurring in children $<15$ yrs of age with an extremely poor prognosis (pleuropulmonary blastomas); and 3) those with a mainly malignant glandular structure of embryonal cells (well-differentiated foetal adenocarcinomas) $[4,5]$. Histologically, the present case belongs to the third type of pulmonary blastoma.

The present case had an atypical manifestation of pulmonary blastoma coexistent with systemic sclerosis. However, the relationship between pulmonary blastoma and systemic sclerosis is obscure [6]. We consider this case to have the features of two different conditions.

The present case also had a remarkably high serum AFP level and the glandular cells of blastomas stained positively against anti-AFP monoclonal antibody. This case was diagnosed as an AFP-producing pulmonary blastoma. AFP is an oncofoetal antigen that is produced from the foetal liver and yolk sac [7] and can be quantitated for confirmation of the diagnosis of hepatocellular carcinoma or germ-cell tumours [8]. Recently, TsuchiDA et al. [9] detected differences in lectin affinity between AFP produced by the foetal liver and AFP produced by the yolk-sac. In the present case, the concanavalin A (ConA) nonreactive fraction rate for serum AFP was $60 \%$ and the reactive fraction was $40 \%$. The lentil agglutinin (LCA) strongly 
Table 1. - Lectin affinity of serum $\alpha$-fetoprotein

\begin{tabular}{lccc}
\hline & Foetal liver & Yolk-sac & Present case \\
& AFP \% & AFP \% & $\%$ \\
\hline ConA reactive & $90-95$ & $45-55$ & 40 \\
ConA nonreactive & $5-10$ & $45-55$ & 60 \\
LCA & $\begin{array}{c}\text { Strongly reactive } \\
\text { and nonreactive } \\
\text { dominant }\end{array}$ & $\begin{array}{c}\text { Strongly reactive and } \\
\text { weakly reactive } \\
\text { dominant }\end{array}$ & $\begin{array}{c}\text { Nonreactive } \\
\text { Weakly reactive }\end{array}$ \\
$\begin{array}{l}\text { Shown are the reactive/nonreactive fractions as \% values of total serum } \alpha \text {-fetoprotein (AFP). ConA: con- } \\
\text { canavalin A; LCA: lentil agglutinin; } \uparrow: \text { increase. }\end{array}$
\end{tabular}

reactive and weakly reactive subfractions were $31 \%$ and $55 \%$ respectively (table 1 ). These results indicated that the AFP of the present case was of yolk-sac origin.

The aetiology of pulmonary blastoma remains obscure because of its rarity. Several hypotheses have been proposed concerning its histogenesis. According to the first theory, supported by BeNsch et al. [10], pulmonary blastoma is a true carcinosarcoma. A second theory is that pulmonary blastoma originates in the bronchial epithelium [11]. The resemblance of epithelial components of the pulmonary blastoma to the foetal lung grandular structure encourages this hypothesis of the endodermal origin of epithelial elements. The third theory proposed by DAVIS et al. [12] suggests that pulmonary blastoma is the malignant change of hamartoma. However, pulmonary blastomas with germ-cell differentiation $[13,14]$ have recently been reported. In these reports, they found the blastomatous areas in the germ-cell component and emphasized the relationship between pulmonary blastoma and yolk-sac tumour histologically. This fourth hypothesis suggests that pulmonary blastoma is a variant of germ-cell malignancy. A high serum concentration of AFP was also recognised in these cases, as in our case. However, immunostaining and the lectin affinity for AFP were not analysed in these reports. In this report, we immunohistochemically detected autonomous AFP production by tumour cells. In addition, this is the first reported case of pulmonary blastoma in which the lectin affinity of AFP was analysed and which indicated that the AFP was of yolk-sac origin.

While it may be argued that the histochemical findings of yolk-sac tumor are not sufficiently established to allow a definitive demonstration of the similarities of immunohistochemistry and lectin affinity with pulmonary blastoma, we submit that our hypothesis is sufficiently compelling to elicit further investigation by investigators with access to more tumours. As such, the present case may shed some light on the path by which further insight into these intriguing tumours might be gained.

\section{References}

1. Barnett N, Barnard WG. Some unusual thoracic tumors. Br J Surg 1945; 32: 447-457.

2. France D, Jacobsen M. Pulmonary blastoma. Curr Top Pathol 1983; 73: 265-294.

3. Ashworth T. Pulmonary blastomas: a true congenital neoplasm. Histopathology 1983; 7: 585-594.

4. Koss MN, Hochholzer L, O'Leary T. Pulmonary blastomas. Cancer 1991; 67: 2368-2381.

5. Chin NK, Lee CN, Lee YS, Tan WC. Pulmonary blastoma in an adult presenting as a chronic loculated effusion: a diagnostic problem. Thorax 1994; 49: 838-839.

6. Rosenthal AK, McLaughlin JK, Gridley G, Nyren O. Incidence of cancer among patients with systemic sclerosis. Cancer 1995; 76: 910-914.

7. Gitlin D. Site of alpha-fetoprotein synthesis. $N$ Engl $J$ Med 1971; 285: 1436-1438.

8. Gitlin D, Perricelli A, Giltin GM. Synthesis of $\alpha$-fetoprotein by liver, yolk sac, and gastrointestinal tract of human conceptus. Cancer Res 1972; 32: 879-892.

9. Tsuchida Y, Fukui M, Sakaguchi H, Ishiguro T. Analysis of lectin affinity immunoelectrophoretic profiles of serum alpha-fetoprotein from patients with yolk sac tumors and carcinomas of the gastrointestinal tract: correlations with molecular structures. Tumor Biol 1989; 10: 289-296.

10. Bensch KG, Bonikos DS, Hockberger PK. Pulmonary carcinoid tumors in tissue and organ culture. Cancer 1976; 38: 2006-2016.

11. Amemiya R, Kodama T, Shimosato Y, Koide T. Three cases of pulmonary blastoma, with special reference to differential diagnosis from carcinomatosa and mixed tumor of salivary gland type. Jpn J Cancer Clin 1977; 23: 123-131.

12. Davis PW, Briggs JC, Seal RM. Benign and malignant mixed tumors of the lung. Thorax 1972; 27: 657-673.

13. Siegel RJ, Bueso-Ramos C, Cohlen C, Koss MN. Pulmonary blastoma with germ cell (yolk sac) differentiation: report of two cases. Mod Pathol 1991; 4: 566-570.

14. Roberta RM, Katerine C, Nevin Murray RC. Primary pulmonary germ cell tumor with blastomatous differentiation. Chest 1994; 106: 1595-1596. 